\title{
Comparison of Life Quality between Diabetic and Diabetic with Tuberculosis Patients
}

\author{
Widuri Wita Andriati Shariefuddin, ${ }^{1}$ Sri Yusnita Irda Sari, ${ }^{2}$ Tri Damiati Pandji ${ }^{3}$ \\ ${ }^{1}$ Faculty of Medicine Universitas Padjadjaran, ${ }^{2}$ Department of Public Health Faculty of Medicine \\ Universitas Padjadjaran, ${ }^{3}$ Department of Physical Medicine and Rehabilitation Faculty of \\ Medicine Universitas Padjadjaran/Dr. Hasan Sadikin General Hospital Bandung
}

\begin{abstract}
Background: There are increasing double burden disease in the world. One of the double burden problems is diabetes mellitus (DM) and Tuberculosis (TB). DM is a metabolic disease while TB is an infectious disease. The increasing number of people with DM and TB will affect the relationship between the two diseases (DMTB). DM is an incurable disease that if it is not controlled properly will affect the person's quality of life. This study was conducted to determine the quality of life (QoL) in people with diabetes compared to diabetic patients who also suffer from tuberculosis at Dr. Hasan Sadikin General Hospital, Bandung.

Methods: This was a cross sectional study which included fifty three respondents in each DM and DM-TB group using the consecutive sampling method. The World Health Organization Quality of Life (WHOQoL$\mathrm{BREF}$ ) questionnaire was given after written informed consent was obtained from respondents. This study was conducted from April to November 2014 at the Endocrine and metabolism policlinic in Dr.Hasan Sadikin General Hospital.

Results: The result showed that the total QoL score of DM patients was 58.8, DM-TB patients was 53.59 which was significantly different between the two groups $(\mathrm{p}=0.004)$. Out of four domains, physical $(\mathrm{p}=0.008)$, psychological $(\mathrm{p}=0.008)$ and environmental health $(\mathrm{p}=0.001)$ were significantly different between the two groups. There was no significant difference in social relationships domain $(p=0.771)$.

Conclusions: Lower QoL among DM-TB patients indicates that improvement in education or counseling particularly about physical, psychological and environment changes is recommended. [AM].2016;3 (3):4405]
\end{abstract}

Keywords: Diabetes mellitus, life quality, tuberculosis

\section{Introduction}

Diabetes mellitus (DM) is a metabolic disorder that causes changes in several organs. Disturbance of these organs will cause a person suffering from diabetes has a big burden in daily life. ${ }^{1}$ Meanwhile, Tuberculosis (TB) is still a major health problem in the world, in 2012 it was reported 8.6 million people were with TB and 1.3 million of them died. ${ }^{2}$

Indonesia ranks $4^{\text {th }}$ highest number of people with diabetes in the world after India, China and the United States. According to the Global Tuberculosis Report 2013, the incidence of TB in Indonesia was ranked $4^{\text {th }}$ in the world. The increasing number of people with TB and DM will affect the relationship between these two diseases. A study conducted in Indonesia, Jakarta and Bandung region, showed the frequency rate of DM in TB (DM-TB) patients was $13.2 \%{ }^{3}$

DM is a lifelong disease which if not handled with proper care can reduce the quality of life (QoL) of patients. Results of a study on quality of life in patients with DM shows that the overall quality of life is good and their perception about health is satisfactory however DM patients are still not satisfied with the psychological side and feel more satisfied when given social support. ${ }^{4}$

Furthermore, studies on quality of life in patients with DM-TB were very limited, thus a study on comparison of life quality between DM patients and DM with TB patients in Bandung, particularly at Dr. Hasan Sadikin General Hospital as the main referral hospital in West Java was highly required. This study was conducted to determine the quality of 
life (QoL) in people with diabetes compared to diabetic patients who also suffer from tuberculosis at Dr. Hasan Sadikin General Hospital, Bandung.

\section{Methods}

This study was a comparative analytic study with a cross-sectional approach. From April to November 2014, 53 patients with diabetic type- 2 and 53 patients with diabetic type2 with tuberculosis at Dr.Hasan Sadikin General Hospital Bandung were enrolled in this study using the consecutive sampling method. The inclusion criteria for this study were registered DM patients and diagnosed with diabetes mellitus type- 2 at the Endocrine and metabolism polyclinic and willing to participate. For the DM-TB group, the inclusion criteria were DM patients who were diagnosed with tuberculosis. DM-TB patients in this study were taken from another study that was conducted at Dr. Hasan Sadikin General Hospital. Meanwhile, the exclusion criteria for this study were patients who did not want to participate and patients who due to mental disorder could not understand and answer the questionnaire. In this study, participants provided informed consent after being acquainted with the purpose of this study. The questionnaire and respondent's identity have been filled by the participant except in some special situations such as the participant could not read clearly or understand the questions.

Furthermore, the WHOQoL-BREF questionnaire had been validated and translated to the Indonesian language. ${ }^{4}$ The questionnaire consists of 26 questions, two questions from the perspective of participants about their general quality of life and general health; the other 24 questions were divided into four domains which were Physical health, Psychological health, Social Relationships, and Environmental health. The answer of each question was being rated on a 5-point Likert scale. The raw score in each domain was then transformed to 1-100 score according to the WHOQoL-BREF guideline. ${ }^{5}$ Data were analyzed using statistical software. The characteristics of respondents were assessed using descriptive statistics and examined then transformed into scores of DM group and DM-TB group using Mann-Whitney test, and the $P$ values less than 0.05 were regarded as significant. Ethical clearance was obtained from Dr. Hasan Sadikin General Hospital before the study was performed.

\section{Results}

The normality test was performed and showed the data were not normally distributed. The characteristic of the study population showed significance differences between the two groups regarding age, sex, level of education, comorbidity and duration of DM participants (Table 1).

Overall, the participant's perception toward their quality of life was similar. The result showed that out of 53 participants, 33 participants from DM group and 32 participants from DM-TB group reported their quality of life was moderately. Moderate health status was reported by 27 respondents $(50.9 \%)$ from both groups.

There were differences in the physical health domain between the two groups, particularly in the dependence on medicinal substances and medical aids to do daily activities $(\mathrm{p}=0.002)$, energy requirement and fatigue $(\mathrm{p}=0.001)$, and ability to do activities in daily live $(\mathrm{p}=0.004)$ (Table 2$)$.

In the psychological health domain there were significant differences between both groups in thinking, learning, memory and concentration $(\mathrm{p}=0.002)$, and self-esteem $(\mathrm{p}=0.010)$ (Table 3$)$.

In the social relationships domain, both groups showed a significance difference in their satisfaction on personal relationships factor $(\mathrm{p}=0.009)$ (Table 4).

The environmental health domain showed that there were significance differences between the two groups in physical environment factor related facilities and infrastructure $(p=0.001)$, opportunity for acquiring new information and skills $(p=0.001)$, recreation factor $(p=0.010)$ and participant satisfaction toward their home environment ( $p=0.001)$ (Table 5).

Furthermore, there was a significant difference in the physical health domain ( $p$ $=0.008)$, psychological health domain ( $\mathrm{p}=$ 0.008 ) and environmental health domain ( $p$ $=0.001$ ). In all four domains, the DM group has higher mean score than the DM-TB group (Table 6).

\section{Discussion}

Previous studies on quality of life in patients with DM-TB were difficult to be found, so this study could not compare the quality of life among the DM-TB group with other studies. The total QoL score in each four domains of QoL among DM patients in this study were 
Table 1 Characteristic of Participants

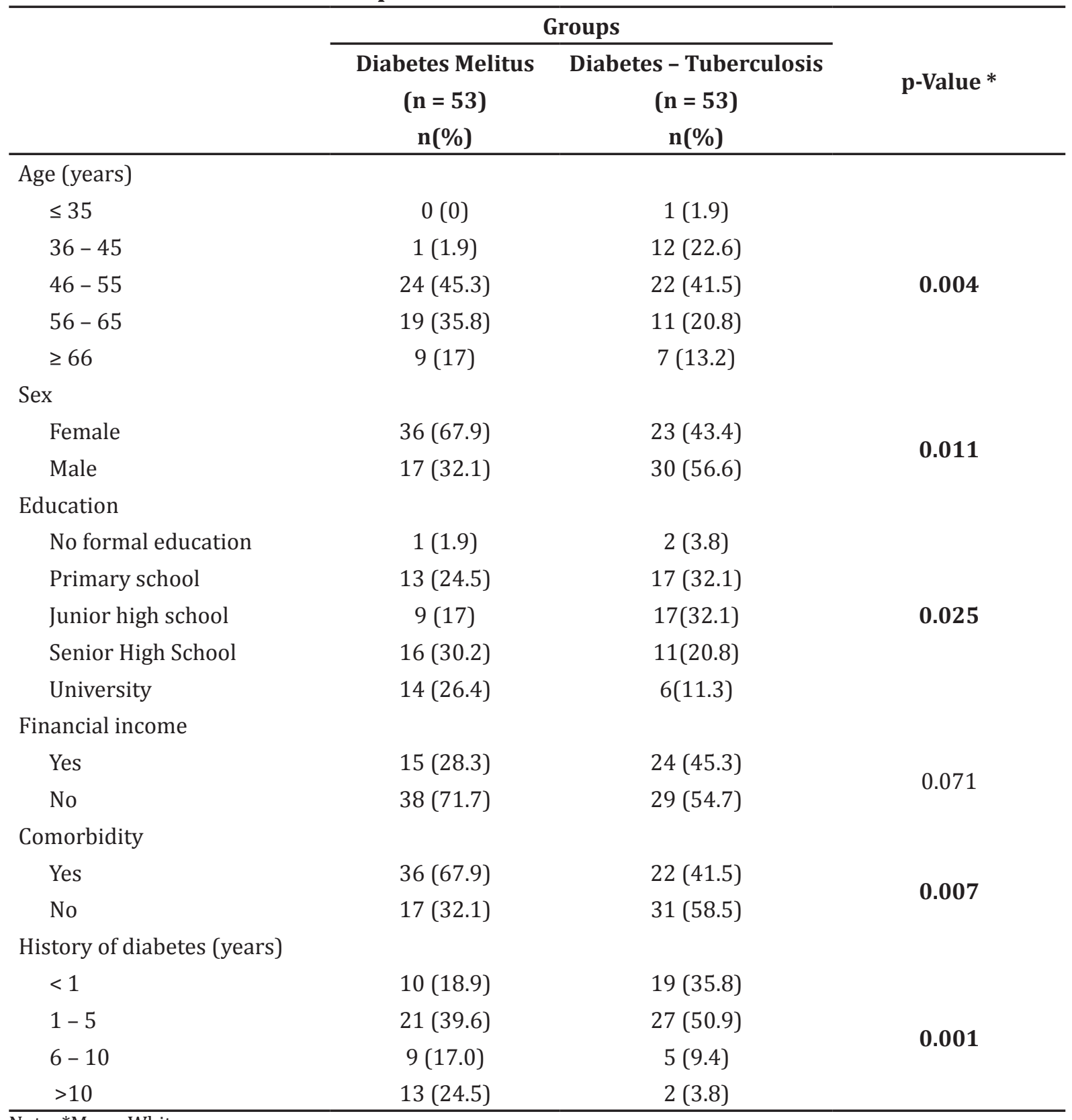

Note: *Mann-Whitney

higher than in studies conducted at Cianjur District Hospital ${ }^{4}$ which is one of the hospitals in West Java Province also in Iran ${ }^{6}$, and Nigeria ${ }^{7}$. There was a big difference in the physical and psychological domain between this study and the study in Iran. The studies in $\operatorname{Iran}^{6}$ and Nigeria $^{7}$ were conducted among respondents who have DM between 6 to 8 years and have low socioeconomic and education level.

Moreover, a study of the quality of life among people with TB was conducted in
Saudi Arabia ${ }^{8}$ where more than half of the respondents have a history of diabetes, the average score in physical health domain was 54.65, psychological health domain was 63.76, social relationships domain was 65.23, and the environment health domain was 64,26. ${ }^{8}$ The study in Saudi Arabia ${ }^{8}$ showed different results from this study because most of the respondents have higher education and socioeconomic status. Additionally, in that study, most of the respondents have an 
Table 2 Participant Quality of Life Based on Physical Health Domain

\begin{tabular}{lccc}
\hline & \multicolumn{2}{c}{ Groups } & \\
\cline { 2 - 3 } & $\begin{array}{c}\text { Diabetes Melitus } \\
(\mathbf{n}=\mathbf{5 3}) \\
\text { Mean (SD**) }\end{array}$ & $\begin{array}{c}\text { Diabetes - Tuberculosis } \\
\mathbf{( n = 5 3 )} \\
\text { Mean (SD) }\end{array}$ & p-Value * \\
\hline Physical Health Domain & $3.04(0.96)$ & $2.83(0.935)$ & \\
$\quad$ Pain & $2.64(0.879)$ & $2.17(0.545)$ & 0.232 \\
Medical therapy & $3.19(0.786)$ & $2.72(0.662)$ & $\mathbf{0 . 0 0 2}$ \\
Energy & $3.64(0.762)$ & $3.62(0.627)$ & $\mathbf{0 . 0 0 1}$ \\
Socialize & $3.21(0.817)$ & $2.94(0.770)$ & 0.740 \\
Rest & $3.26(0.684)$ & $2.94(0.534)$ & 0.630 \\
Activity & $3.19(0.786)$ & $3.00(0.650)$ & $\mathbf{0 . 0 0 4}$ \\
Ability to work & & & 0.144 \\
\hline
\end{tabular}

Note: *Mann-Whitney, ${ }^{* *} \mathrm{SD}=$ Standard deviation

occupation. Therefore, it could not compare the result with this study since only half of the respondents had a history of DM.

Results of the average score between the DM group and DM-TB group showed that the DM group had higher average score of quality of life, thus it could be concluded that the quality of life in theDM group was better than in the DM-TB group. ${ }^{5}$ This result might be due to a person who had been suffering from a chronic disease such as diabetes, then also had other diseases or comorbidities such as $\mathrm{TB}$, which could imply worsen of the condition and would result in the reduction in score of quality of life.

Moreover, DM and TB can cause decrease in immunity. It will make the person with DM-TB has limited activity and ability to work. Other things that can provide an effect of a decrease in the quality of life is that people with DM who also suffer from TB is psychological termed because a person who has TB still received a bad stigma from the community. ${ }^{9}$ Moreover, tuberculosis patients can reduce their quality of life in terms of physical health domain, a person who has TB will have more symptoms such as cough and night sweats so it will affect their comfort in daily activities or sleep. DM patients with TB will receive a number of medical therapy more than DM patients so it can reduce the level of compliance of participants, TB treatment can also give side effects such as tiredness, nausea, psychological disorders, disorders of the kidneys and liver, ${ }^{10,11}$ this condition can also cause the quality of life in terms of physical health and psychological

Table 3 Participant Quality of Life Based on Psychological Health Domain

\begin{tabular}{|c|c|c|c|}
\hline & \multicolumn{2}{|c|}{ Groups } & \multirow[b]{2}{*}{ p-Value * } \\
\hline & $\begin{array}{c}\text { Diabetes Melitus } \\
\qquad(\mathrm{n}=53) \\
\text { Mean }\left(\mathrm{SD}^{* *}\right) \\
\end{array}$ & $\begin{array}{l}\text { Diabetes - Tuberculosis } \\
\qquad(\mathrm{n}=53) \\
\text { Mean (SD) } \\
\end{array}$ & \\
\hline \multicolumn{4}{|c|}{ psychological health domain } \\
\hline Positive feelings & $3.34(0.586)$ & $3.21(0.6890$ & 0.354 \\
\hline Spirituality & $3.55(0.774)$ & $3.30(0.607)$ & 0.102 \\
\hline Thinking & $3.32(0.803)$ & $2.79(0.840)$ & 0.002 \\
\hline Bodily image & $3.30(0.845)$ & $3.26(0.655)$ & 0.704 \\
\hline Self esteem & $3.42(0.692)$ & $3.13(0.590)$ & 0.010 \\
\hline Negative feelings & $4.08(0.805)$ & $3.85(0.818)$ & 0.141 \\
\hline
\end{tabular}

Note: *Mann-Whitney, **SD=Standard deviation 
Table 4 Participant Quality of Life Based on Social Relationships Domain

\begin{tabular}{lccc}
\hline & \multicolumn{2}{c}{ Groups } & \\
\cline { 2 - 3 } & $\begin{array}{c}\text { Diabetes Melitus } \\
(\mathbf{n}=\mathbf{5 3}) \\
\text { Mean (SD**) }\end{array}$ & $\begin{array}{c}\text { Diabetes - Tuberculosis } \\
(\mathbf{n}=\mathbf{5 3}) \\
\text { Mean (SD) }\end{array}$ & p-Value * \\
\hline Social relationships domain & & & \\
$\quad$ Personal relationships & $3.32(0.613)$ & $3.00(0.555)$ & $\mathbf{0 . 0 0 9}$ \\
Sexual life & $3.08(0.874)$ & $3.21(0.600)$ & 0.408 \\
$\quad$ Social support & $3.70(0.799)$ & $3.79(0.613)$ & 0.518 \\
\hline Note: ${ }^{*}$ Mann-Whitney, ${ }^{* *}$ SD=Standard deviation & &
\end{tabular}

Table 5 Participant Quality of Life Based on Environmental Health Domain

\begin{tabular}{lccc}
\hline & \multicolumn{2}{c}{ Groups } & \\
\cline { 2 - 3 } & $\begin{array}{c}\text { Diabetes Melitus } \\
(\mathbf{n}=\mathbf{5 3}) \\
\text { Mean (SD**) }\end{array}$ & $\begin{array}{c}\text { Diabetes - Tuberculosis } \\
\text { (n = 53) } \\
\text { Mean (SD) }\end{array}$ & p-Value * \\
\hline Environmental health domain & & & \\
$\quad$ Physical safety & $3.26(0.984)$ & $2.96(0.587)$ & 0.061 \\
Physical environment & $3.57(0.694)$ & $3.11(0.640)$ & $\mathbf{0 . 0 0 1}$ \\
Financial resources & $2.98(0.604)$ & $3.00(0.392)$ & 0.650 \\
New information & $3.42(0.9490$ & $2.58(0.770)$ & $\mathbf{0 . 0 0 1}$ \\
Recreation & $2.72(0.928)$ & $2.26(0.788)$ & $\mathbf{0 . 0 1 0}$ \\
Home environment & $3.66(0.706)$ & $3.25(0.617)$ & $\mathbf{0 . 0 0 1}$ \\
Health and social care & $3.62(0.713)$ & $3.72(0.662)$ & 0.180 \\
Transport & $3.28(0.794)$ & $3.21(0.532)$ & 0.271 \\
\hline
\end{tabular}

Note: *Mann-Whitney, ${ }^{*} \mathrm{SD}=$ Standard deviation

Table 6 Comparison between Transformed Scores of the WHOQoL-BREF in Total and its Four Domains

\begin{tabular}{|c|c|c|c|}
\hline & \multicolumn{2}{|c|}{ Groups } & \multirow[b]{2}{*}{ p-Value * } \\
\hline & $\begin{array}{c}\text { Diabetes Melitus } \\
\quad(\mathrm{n}=53) \\
\text { Mean }\left(\mathrm{SD}^{* *}\right)\end{array}$ & $\begin{array}{c}\text { Diabetes - Tuberculosis } \\
(n=53) \\
\text { Mean (SD) }\end{array}$ & \\
\hline \multicolumn{4}{|l|}{ Domain } \\
\hline Physical Health & $54.32(13.68)$ & $47.42(9.754)$ & 0.008 \\
\hline Psychological health & 62.43 (12.19) & $56.25(11.021)$ & 0.008 \\
\hline Social relationship & $58.94(14.58)$ & $58.64(11.196)$ & 0.771 \\
\hline Environmental health & 59.49 (11.09) & $52.06(6.860)$ & 0.001 \\
\hline Total & $58.80(10.70)$ & $53.59(7.12)$ & 0.004 \\
\hline
\end{tabular}


health reduce and can make the patients become depressed. ${ }^{12}$ Necessary provision of information and monitoring of the side effects of a given drugs, social support from family and other close friends to patients with DM or DM-TB is needed especially for DM-TB group. ${ }^{13}$

There was a time limit in this study which caused some of the DM-TB participants were in the intermittent phase of TB treatment, and it might cause any TB sign or symptom diminished and their quality of life began to increase.

Based on this study, it can be concluded that the average life quality score in the diabetic group is higher than in the diabetic with tuberculosis group in all four domains. Moreover, there is a significant difference in the total life quality, physical health, psychological health and environmental health domain. From these study findings, it is suggested to conduct follow up studies to identify the quality of life because the quality of life is related with how the patients are treated and linked with their psychological health. Additionally, hospitals/primary health cares need to maintain and improve their care for patients by improvements in information and health education about the relation between diabetes and tuberculosis.

\section{References}

1. Longo DL, Kasper DL, Jameson JL, Fauci AS, Hauser SL, Loscalzo J, editors. Harrison' ${ }^{\mathrm{TM}}$ principle of internal medicine. 18th ed. United States of America: The McGraw-Hill Companies, Inc.; 2012.

2. World Health Organization. Global Tuberculosis Report 2013. Geneva: WHO, 2013.

3. Bachti Alisjahbana, van Crevel R, Edhyana Sahiratmadja, den Heijer M, Anugrah Maya, Erita Istriana, et al. Diabetes mellitus is strongly associated with tuberculosis in Indonesia. Int $\mathrm{J}$ Tuberc Lung Dis. 2006;10(6):696-700.

4. Kurniawan Yudianto, Hana Rizmadewi, Ida Maryati. Kualitas hidup penderita diabetes melitus di Rumah Sakit Umum Daerah
Cianjur. Jurnal Keperawatan Padjadjaran. 2008;10:76-86.

5. World Health Organization. WHOQOLBREF: introduction, administration, scoring and generic version of the assessment. Geneva: WHO; 1996.

6. Gholani A, Azini M, Borji A. Quality of life in patients with type 2 diabetes: application of WHOQoL-BREF scale. Shiraz E medical Journal. 2013;14:162-71.

7. Kolawole BA, Mosaku SK, Ikem RT. A Comparison of two measures of quality of life of Nigerian clinic patients with type 2 Diabetes Mellitus. African Health Sciences. 2009;9(3):161-6.

8. Al-Qahtani MF, El.Mahalli AA, Al Dossary $\mathrm{N}$, Al Muhaish A, Al Otaibi S, Al Baker F. Health-related quality of life of tuberculosis patients in the Eastern Province, Saudi Arabia. Journal of Taibah University Medical Sciences. 2014;9(4):311-7.

9. Courtwright A, Turner AN. Tuberculosis and stigmatization: pathways and interventions. Public health reports (Washington, DC : 1974). 2010;125 Suppl 4:34-42.

10. Gulbay BE, Gurkan OU, Yildiz OA, Onen ZP, Erkekol FO, Baccioglu A, et al. Side effects due to primary antituberculosis drugs during the initial phase of therapy in 1149 hospitalized patients for tuberculosis. Respiratory medicine. 2006;100(10):1834-42.

11. Torun T, Gungor G, Ozmen I, Bolukbasi Y, Maden E, Bicakci B, et al. Side effects associated with the treatment of multidrugresistant tuberculosis. Int J Tuberc Lung Dis. 2005;9(12):1373-7.

12. Pan A, Lucas $M$, Sun $Q$, van Dam RM, Franco OH, Manson JE, et al. Bidirectional association between depression and type 2 diabetes mellitus in women. Arch Intern Med. 2010;170(21):1884-91.

13. Melisa Prisilia Terok, Jeavery Bawotong, Frenly Muntu Untu. Hubungan dukungan sosial dengan kualitas hidup pada pasien tuberkulosis paru di Poli BLU RSUP Prof. DR. R. D Kandou Manado. E Journal Keperawatan. 2012;1:1-10. 